\title{
Gene Panel Screening Across Canine Eye Disorders Highlights Genetic Heterogeneity and the Need for Molecular Discoveries
}

Inka-Tuulevi Pettinen

University of Helsinki: Helsingin Yliopisto

Jonas Donner

Genoscoper Laboratories

Joni A. Turunen

University of Helsinki: Helsingin Yliopisto

Maria Kaukonen

University of Helsinki: Helsingin Yliopisto

Hannes Lohi ( $\nabla$ hannes.lohi@helsinki.fi)

Helsingin Yliopisto Laaketieteellinen tiedekunta https://orcid.org/0000-0003-1087-5532

\section{Research Article}

Keywords: dog, eye, disorder, gene panel, sequencing

Posted Date: April 20th, 2021

DOI: https://doi.org/10.21203/rs.3.rs-417922/v1

License: (c) (i) This work is licensed under a Creative Commons Attribution 4.0 International License. Read Full License 


\section{Abstract}

Blinding inherited eye diseases affect millions of people worldwide. Despite a large number of gene discoveries, many patients lack the molecular description of their condition. The domestic dog has become a widely used model to study inherited eye disease genetics and therapeutics during the past 15 years, and nearly 50 genes have been implicated across breeds. Despite a continuous discovery of new causative variants across canine eye disease groups, the genetic cause in most cases is expected to remain unknown. We tested this hypothesis by screening 49 known variants in 194 dogs from 71 breeds affected with progressive retinal atrophy (PRA), glaucoma, or lens luxation and validated the results in additional 1180 dogs. We found that eleven variants in ten genes explained $28 \%$ of the studied cases. We also observed new PRA-affected breeds for the RPGRIP1 c.340_341 insA ${ }_{29}$ GGAAGCAACAGGATG variant, and clinical support for the pathogenicity of the PDE6A c.1940delA and ADAMTS10 c.2231G>A variants for PRA and glaucoma in two new breeds, respectively. Our findings indicate extensive genetic heterogeneity and the lack of molecular descriptions in more than two-thirds of the LL, glaucoma, and PRA cases by the current gene tests. There is an urgent need for discoveries that would be critical not only for veterinary molecular diagnostics and breeding programs but also for establishing models to characterize pathophysiology and new therapeutic options for the corresponding human eye disorders.

\section{Introduction}

Over two billion people worldwide suffer from varying eye diseases affecting their quality of life (Assi et al., 2021). Inherited conditions such as retinitis pigmentosa (RP), ectopia lentis (EL), and glaucoma have both isolated and syndromic forms with onsets ranging from congenital to late adulthood (Daiger et al., 2007; Lenassi et al., 2020; Overwater et al., 2017; Wiggs, 2015). For example, over 65 genes, to date, are known to cause isolated RP (RetNet, https://sph.uth.edu/RetNet/), Daiger et al., 2007).

During the past 15 years, due to their similar eye physiologies and retinal metabolism, the dog has become a favorite spontaneous large animal model to study the genetics of inherited eye diseases. This has been facilitated by their distinctive population structure, which results from multiple evolutionary bottlenecks (Lindblad-Toh et al., 2005). Inbreeding and popular sires have diminished genetic variation within breeds and have contributed to the number of eye diseases observable today by enriching the disease-causing variants (Aguirre-Hernández \& Sargan, 2005). Interestingly, due to their relatively short breedspecific histories, large-scale studies have revealed a widespread presence of recessive pathogenic variants across the general dog population, but notably higher disease case prevalence in pure breeds (Donner et al., 2016, 2018). For example, over 100 breeds to date are known to be affected by progressive retinal atrophy (PRA), the canine equivalent of human RP, which affects millions of individuals worldwide (Haim, 2002; Petersen-Jones \& Komáromy, 2014).

The benefits of using the dog as a spontaneous model to study many human eye diseases have been of growing emphasis from the 1980s onwards when genes of the phosphodiesterase-family were established as harboring causative variants to both the canine PRA and human RP40 (Aguirre et al., 2007; Bunel et al., 2019; Dekomien \& Epplen, 2003; Dvir et al., 2010; Miyadera et al., 2012; Suber et al., 1993). Since then, at least 15 genes have been observed to be altered in both PRA and RP (Online Mendelian Database, OMIA, https://omia.org/; RetNet, https://sph.uth.edu/RetNet/). A similar pattern can be further recognized for glaucoma and ectopia lentis (EL), a canine equivalent of lens luxation (LL): ADAM metallopeptidase with thrombospondin type 1 motif- proteins - ADAMTS10 and ADAMTS17-genes have been observed to harbor variants causative for primary glaucoma and LL in dogs and syndromic diseases, with symptoms including glaucoma and EL, in humans (WeillMarchessani syndrome) (Farias et al., 2010; Forman et al., 2015; Jeanes et al., 2019; Morales et al., 2009). Overall, this pattern of shared genes harboring eye disease-causing variants indicates a need for further research in both species. Furthermore, the comparable phenotypes and genotypes have allowed meticulous studying of the pathophysiology and successful testing of therapies - especially gene therapies - in dogs (Aguirre et al., 2007; Petersen-Jones \& Komáromy, 2014).

To date, genetic testing for inherited canine eye diseases, both syndromic and non-syndromic, is available for more than 60 variants in nearly 50 genes (OMIA, https://omia.org/). These variants represent occurring phenotypes detected in over 130 
breeds, yet many eye diseases across multiple breeds have unknown genetic risk factors.

Here, we demonstrate that gene panel screening of a cohort of 194 dogs from 71 breeds identifies the causative mutation in only $28 \%$ of the LL, glaucoma, and PRA cases. The blinding conditions in most breeds are not explained by any of the tested 49 known eye disease variants. Future research is urgently needed to improve veterinary diagnostics, breeding plans and establish disease models to the corresponding human conditions.

\section{Materials And Methods}

\section{Study cohorts}

The gene panel cohort study cohort was established from the dog biobank at the University of Helsinki. The cohort included 194 privately owned purebred pet dogs from 71 breeds with a diagnosis of LL affected ( $n=22)$ and LL suspected ( $n=14)$, glaucoma affected $(n=28)$ and glaucoma suspected $(n=2)$, PRA affected $(n=115)$ and PRA suspected $(n=3)$, other retinopathy affected $(n=6)$, or other retinopathy suspected $(n=2)$, and dogs affected with overlapping PRA and glaucoma $(n=2)($ Table 1$)$. The gene panel cohort included 110 males, 82 females, and two dogs of unknown gender. All dogs had been eye examined by veterinary ophthalmologists board-certified by the European College of Veterinary Ophthalmologists (ECVO). For clarity, we refer to cases in each phenotype with either affected or suspected diagnosis.

To validate the gene panel cohort's preliminary findings, a validation cohort with additional 1180 samples was selected from the dog biobank at the University of Helsinki. The validation cohort included dogs from six breeds (Table 1) not included in the gene panel cohort. These breeds are known to carry both the RPGRIP1 c.340_341 insA ${ }_{29}$ GGAAGCAACAGGATG insertion and MAP9 deletion variants based on the commercial genetic testing results at Wisdom Health. We also included samples from two other additional breeds, East Siberian Laikas ( $E S L, n=71)$ and Labrador Retrievers ( $L R, n=190)$, to test the presence of the ADAMTS10 c. $2231 \mathrm{G}>\mathrm{A}$ glaucoma associated variant and the TTC8 c.669delA PRA associated variant, respectively. We had been contacted by an owner of an ESL that had been tested heterozygous for the ADAMTS10 variant in a commercial gene test and screened for the frequency of the variant in our samples. Also, we wanted to know the possible presence of the TTC8 variant in the Finnish LR population, as reported in LR populations outside Finland (Downs et al., 2014).

Table 1. Summary of breeds, sample numbers, and variants selected for the screening (gene panel cohort, $n=194$ ) and validation (validation cohort, $\mathrm{n}=1180$ ) of the known eye disease variants. 


\begin{tabular}{|c|c|c|c|c|}
\hline Breed & Disease & $\begin{array}{l}\text { Gene panel cohort } \\
\text { affected/suspected (n) }\end{array}$ & $\begin{array}{l}\text { Validation } \\
\text { cohort (n) }\end{array}$ & Gene variant \\
\hline Airedale Terrier & PRA & $9 / 0$ & 0 & - \\
\hline Alaskan Malamute & PRA & $1 / 0$ & 0 & - \\
\hline $\begin{array}{l}\text { American Cocker } \\
\text { Spaniel }\end{array}$ & Glaucoma & $1 / 0$ & 0 & - \\
\hline $\begin{array}{l}\text { American Hairless } \\
\text { Terrier }\end{array}$ & PRA & $1 / 0$ & 0 & - \\
\hline $\begin{array}{l}\text { American } \\
\text { Staffordshire Terrier }\end{array}$ & - & $0 / 0$ & 3 & $\begin{array}{l}\text { RPGRIP1 insertion and } \\
M A P 9 \text { deletion }\end{array}$ \\
\hline $\begin{array}{l}\text { Australian Cattle } \\
\text { Dog }\end{array}$ & Lens luxation PRA & $1 / 02 / 0$ & 0 & - \\
\hline Australian Kelpie & PRA & $1 / 0$ & 0 & - \\
\hline Barbet & - & $0 / 0$ & 21 & $\begin{array}{l}\text { RPGRIP1 insertion and } \\
\text { MAP9 deletion }\end{array}$ \\
\hline Basenji & PRA & $1 / 0$ & 0 & - \\
\hline Beagle & - & $0 / 0$ & 33 & $\begin{array}{l}\text { RPGRIP1 insertion and } \\
\text { MAP9 deletion }\end{array}$ \\
\hline Bolognese & PRA & $2 / 0$ & 0 & - \\
\hline Border Collie & PRA & $1 / 0$ & 0 & - \\
\hline Cairn Terrier & Glaucoma & $1 / 0$ & 0 & - \\
\hline $\begin{array}{l}\text { Ceskoslovensky } \\
\text { vlcak }\end{array}$ & Lens luxation & $1 / 0$ & 0 & - \\
\hline Chihuahua & PRA & $5 / 0$ & 199 & $\begin{array}{l}\text { RPGRIP1 insertion and } \\
\text { MAP9 deletion }\end{array}$ \\
\hline $\begin{array}{l}\text { Chinese Crested } \\
\text { Dog }\end{array}$ & Lens luxation PRA & $3 / 72 / 0$ & 105 & $\begin{array}{l}\text { RPGRIP1 insertion and } \\
M A P 9 \text { deletion }\end{array}$ \\
\hline Rough Collie & Glaucoma PRA & $1 / 01 / 0$ & 0 & - \\
\hline Coton de Tulear & PRA & $2 / 0$ & 25 & $\begin{array}{l}\text { RPGRIP1 insertion and } \\
\text { MAP9 deletion }\end{array}$ \\
\hline $\begin{array}{l}\text { Curly Coated } \\
\text { Retriever }\end{array}$ & PRA & $1 / 0$ & 0 & - \\
\hline $\begin{array}{l}\text { Long-haired } \\
\text { Dachshund }\end{array}$ & PRA & $1 / 0$ & 10 & $\begin{array}{l}\text { RPGRIP1 insertion and } \\
M A P 9 \text { deletion }\end{array}$ \\
\hline $\begin{array}{l}\text { Short-haired } \\
\text { Dachshund }\end{array}$ & PRA & $1 / 0$ & 3 & $\begin{array}{l}\text { RPGRIP1 insertion and } \\
M A P 9 \text { deletion }\end{array}$ \\
\hline $\begin{array}{l}\text { Wire-haired } \\
\text { Dachshund }\end{array}$ & PRA & $1 / 0$ & 27 & $\begin{array}{l}\text { RPGRIP1 insertion and } \\
\text { MAP9 deletion }\end{array}$ \\
\hline $\begin{array}{l}\text { Dandie Dinmont } \\
\text { Terrier }\end{array}$ & Glaucoma & $6 / 0$ & 0 & - \\
\hline East Siberian Laika & - & $0 / 0$ & 71 & $\begin{array}{l}\text { ADAMTS10 } \\
\text { c. } 2231 \mathrm{G}>\mathrm{A}\end{array}$ \\
\hline English Setter & PRA & $1 / 0$ & 0 & - \\
\hline
\end{tabular}




\begin{tabular}{|c|c|c|c|c|}
\hline $\begin{array}{l}\text { English Springer } \\
\text { Spaniel }\end{array}$ & $\begin{array}{l}\text { Glaucoma Lens luxation } \\
\text { PRA PRA \& glaucoma }\end{array}$ & $2 / 01 / 01 / 01 / 0$ & 0 & - \\
\hline English Toy Terrier & Lens luxation PRA & $1 / 02 / 0$ & 114 & $\begin{array}{l}R P G R I P 1 \text { insertion and } \\
\text { MAP9 deletion }\end{array}$ \\
\hline $\begin{array}{l}\text { Entlebucher } \\
\text { Mountain Dog }\end{array}$ & Glaucoma & $1 / 0$ & 0 & - \\
\hline Finnish Lapphund & Glaucoma PRA & $3 / 05 / 0$ & 0 & - \\
\hline $\begin{array}{l}\text { Flat-Coated } \\
\text { Retriever }\end{array}$ & Glaucoma & $1 / 0$ & 0 & - \\
\hline $\begin{array}{l}\text { German Hunting } \\
\text { Terrier }\end{array}$ & PRA & $1 / 0$ & 0 & - \\
\hline German Spitz & PRA & $2 / 0$ & 0 & - \\
\hline Golden Retriever & PRA & $1 / 0$ & 0 & - \\
\hline Great Dane & Lens luxation & $1 / 0$ & 0 & - \\
\hline Griffon Belge & Lens luxation & $1 / 1$ & 0 & - \\
\hline Havanese & PRA & $2 / 0$ & 0 & - \\
\hline Irish (Red) Setter & PRA & $2 / 0$ & 0 & - \\
\hline Jack Russell Terrier & Lens luxation & $1 / 2$ & 0 & - \\
\hline Karelian Bear Dog & PRA Other retinopathy & $9 / 16 / 2$ & 0 & - \\
\hline Kromfohrländer & Lens luxation & $1 / 1$ & 0 & - \\
\hline Labrador Retriever & - & $0 / 0$ & 190 & TTC8 c.669delA \\
\hline Lagotto Romagnolo & PRA & $1 / 0$ & 0 & - \\
\hline Lancashire Heeler & Lens luxation & $1 / 1$ & 0 & - \\
\hline Lapponian Herder & Lens luxation PRA & $1 / 01 / 0$ & 0 & - \\
\hline Leonberger & Glaucoma & $1 / 0$ & 0 & - \\
\hline Lowchen & PRA & $1 / 0$ & 95 & $\begin{array}{l}\text { RPGRIP1 insertion and } \\
\text { MAP9 deletion }\end{array}$ \\
\hline $\begin{array}{l}\text { Miniature Bull } \\
\text { Terrier }\end{array}$ & Lens luxation & $3 / 1$ & 0 & - \\
\hline $\begin{array}{l}\text { Miniature long- } \\
\text { haired Dachshund }\end{array}$ & - & $0 / 0$ & 24 & $\begin{array}{l}\text { RPGRIP1 insertion and } \\
M A P 9 \text { deletion }\end{array}$ \\
\hline $\begin{array}{l}\text { Miniature short- } \\
\text { haired Dachshund }\end{array}$ & - & $0 / 0$ & 14 & $\begin{array}{l}\text { RPGRIP1 insertion and } \\
\text { MAP9 deletion }\end{array}$ \\
\hline $\begin{array}{l}\text { Miniature wire- } \\
\text { haired Dachshund }\end{array}$ & - & $0 / 0$ & 12 & $\begin{array}{l}R P G R I P 1 \text { insertion and } \\
M A P 9 \text { deletion }\end{array}$ \\
\hline $\begin{array}{l}\text { Miniature } \\
\text { Schnauzer }\end{array}$ & PRA PRA \& glaucoma & $8 / 01 / 0$ & 0 & - \\
\hline Norfolk Terrier & PRA & $2 / 0$ & 0 & - \\
\hline $\begin{array}{l}\text { Grey Norwegian } \\
\text { Elkhound }\end{array}$ & $\begin{array}{l}\text { Glaucoma Lens luxation } \\
\text { PRA }\end{array}$ & $4 / 21 / 02 / 0$ & 0 & - \\
\hline $\begin{array}{l}\text { Nova Scotia Duck } \\
\text { Tolling Retriever }\end{array}$ & PRA & $8 / 0$ & 0 & - \\
\hline
\end{tabular}




\begin{tabular}{|c|c|c|c|c|}
\hline $\begin{array}{l}\text { Old English } \\
\text { Sheepdog }\end{array}$ & PRA & $1 / 0$ & 0 & - \\
\hline Papillon & PRA & $4 / 0$ & 0 & - \\
\hline $\begin{array}{l}\text { Parson Russell } \\
\text { Terrier }\end{array}$ & Lens luxation & $2 / 0$ & 0 & - \\
\hline $\begin{array}{l}\text { Peruvian Hairless } \\
\text { Dog }\end{array}$ & PRA & $1 / 0$ & 0 & - \\
\hline Phalene & PRA & $1 / 0$ & 0 & - \\
\hline Picardy Sheepdog & PRA & $1 / 0$ & 0 & - \\
\hline $\begin{array}{l}\text { Polish Lowland } \\
\text { Sheepdog }\end{array}$ & PRA & $2 / 0$ & 0 & - \\
\hline Pomeranian & PRA & $1 / 0$ & 44 & PDE6A c.1940delA \\
\hline $\begin{array}{l}\text { Portuguese } \\
\text { Podengo Pequeno }\end{array}$ & PRA & $4 / 1$ & 0 & - \\
\hline $\begin{array}{l}\text { Portuguese Water } \\
\text { Dog }\end{array}$ & PRA & $2 / 0$ & 0 & - \\
\hline Rottweiler & PRA & $0 / 1$ & 0 & - \\
\hline Saarlooswolfdog & PRA & $2 / 0$ & 0 & - \\
\hline Samoyed & Glaucoma & $2 / 0$ & 0 & - \\
\hline Schipperke & PRA & $1 / 0$ & 0 & - \\
\hline Shetland Sheepdog & PRA & $1 / 0$ & 0 & - \\
\hline Siberian Husky & Glaucoma & $2 / 0$ & 0 & - \\
\hline Spanish Water Dog & Lens luxation PRA & $1 / 02 / 0$ & 0 & - \\
\hline $\begin{array}{l}\text { Staffordshire Bull } \\
\text { Terrier }\end{array}$ & PRA & $1 / 0$ & 0 & - \\
\hline Swedish Elkhound & PRA & $2 / 0$ & 94 & $\begin{array}{l}R P G R I P 1 \text { insertion and } \\
\text { MAP9 deletion }\end{array}$ \\
\hline Tibetan Mastiff & PRA & $1 / 0$ & 0 & - \\
\hline Tibetan Spaniel & PRA & $5 / 0$ & 0 & - \\
\hline Tibetan Terrier & Lens luxation & $1 / 1$ & 0 & - \\
\hline $\begin{array}{l}\text { Welsh Springer } \\
\text { Spaniel }\end{array}$ & Glaucoma & $3 / 0$ & 0 & - \\
\hline Whippet & Lens luxation & $1 / 0$ & 0 & - \\
\hline $\begin{array}{l}\text { White Swiss } \\
\text { Shepherd Dog }\end{array}$ & PRA & $2 / 0$ & 0 & - \\
\hline
\end{tabular}

EDTA blood samples (1-3 ml) were collected from the dogs and submitted to the biobank with the dog owners' written consent over the past ten years. The study was conducted under the permission of the animal ethical committee of the County Administrative Board of Southern Finland (ESAVI/25696/2020).

\section{DNA isolation}


Genomic DNA was extracted from the EDTA blood samples using a semi-automated Chemagen extraction robot (PerkinElmer Chemagen Technologie $\mathrm{GmbH}$, Baeswieler, Germany) according to the manufacturer's instructions. DNA concentration and purity were assessed by using the Qubit fluorometer (Thermo Fisher Scientific, Waltham, MA, USA) and Nanodrop ND-1000 UV/Vis Spectrophotometer (Nanodrop technologies, Wilmington, DE, USA) and samples were stored at $+4^{\circ} \mathrm{C}$ (dilutions) and $-20^{\circ} \mathrm{C}$ (stocks).

\section{Gene panel screening}

Genotyping of 49 eye disease variants in 36 genes, including 12 variants associated with syndromic diseases with eye phenotypes (Online resource 1), was carried out according to manufacturer-recommended standard protocols on a customdesigned Illumina Infinium XT genotyping bead chip (Illumina, San Diego, CA, USA) commercially available as the MyDogDNA $^{\text {TM }}$ or Optimal Selection ${ }^{\text {TM }}$ test (Wisdom Health, Vancouver, WA, USA). The design, validation, and use of the custom-designed genotyping array to explore canine diseases and traits have been described in detail earlier (Donner et al., 2016, 2018; Dreger et al., 2019).

\section{Validation screening}

Genotyping for validation cohorts (Table 1) was performed by PCR and Sanger sequencing. Most primers (Online resource 2) were designed with Primer3 software, and PCRs were performed using Biotools DNA Polymerase (Biotools B\&M Labs, S.A., Valle de Tobalina, Madrid, Spain). Sequencing was done in our institutional core facility, FIMM Technology Center (Helsinki, Finland), using an ABI 3730xI DNA analyzer (Applied Biosystems, Foster City, California, USA). Sequence data analysis was performed using BioEdit software (Version 7.0.5.3; Hall, 1999) and Unipro UGENE v35.0 (UniPro, Novosibirsk, Russia). Primer sequences for the MAP9 deletion were obtained from the publication by Forman et al. 2016, and the PCR was done using KAPA HiFi HotStart ReadyMix (Roche, Penzberg, Upper Bavaria, Germany). RPGRIP1 insertion primer sequences were obtained from the publication by Miyadera et al., 2009, and PCRs were performed using Biotools DNA Polymerase (Biotools B\&M Labs, S.A., Valle de Tobalina, Madrid, Spain). Due to the size of the RPGRIP1 insertion (44 bp), the PCR products were run on $1.5 \%$ agarose gel for $1.5 \mathrm{~h}$. The MAP9 deletion PCR-products (10k bp) were run on $1 \%$ agarose gels for $40 \mathrm{~min}$. The genotypes were analyzed from the gels imaged with the ChemiDoc MP imaging system (Hercules, California, United States).

\section{Optical coherence tomography imaging}

To examine the retinal phenotype associated with the RPGRIP1 insertion variant in a higher resolution, spectral-domain optical coherence tomography (SD-OCT) imaging was performed using the Heidelberg Spectralis HRA+OCT instrument (Heidelberg Engineering, Heidelberg, Germany) in the Department of Ophthalmology, Helsinki University Hospital, Helsinki, Finland. We invited five dogs homozygous for the RPGRIP1 insertion, wild-type for the MAP9 deletion, and three age- and breed-matched controls (RPGRIP1 insertion wild-type, MAP9 deletion wild-type) for SD-OCT. Three of the RPGRIP1 insertion homozygotes were beagles, one was American Staffordshire Terrier, and one was Miniature Shorthaired Dachshund. Their ages ranged between 1.3-7.8 years.

\section{Results}

\section{Gene panel screening reveals genetic heterogeneity in eye disorders}

To understand the extent of the genetic heterogeneity and how well the current eye disease gene panel detects genetic causes in affected dogs, we selected 194 eye disease-affected dogs from 71 breeds to be screened for 49 known eye disease variants in 36 genes (Online resource 1). We found causative variants only in 53 affected dogs, representing only $28 \%$ of the gene panel cohort (Table 2). The identified eleven causative variants in ten genes are specified in Table 3.

Table 2. Summary of the genetic causes identified by the gene panel screening by eye disease groups (53/194; 28\%). 


\begin{tabular}{|lll|}
\hline Eye disease & Affected or suspected dogs $(\mathbf{n})$ & Dogs with genetic cause found (n) (\%) \\
\hline Lens luxation & 36 & $16(44)$ \\
\hline Glaucoma & 30 & $5(17)$ \\
\hline Progressive retinal atrophy & 118 & $32(27)$ \\
\hline Other retinopathy & 8 & 0 \\
\hline Progressive retinal atrophy and glaucoma & 2 & 0 \\
\hline
\end{tabular}

Table 3. Summary of the gene panel screening results in 194 dogs. New affected breeds are bolded. 


\begin{tabular}{|c|c|c|c|}
\hline Phenotype and gene variant & $\begin{array}{l}\text { Breed(s) variant observed } \\
\text { in }\end{array}$ & $\begin{array}{l}\text { Homozygotes } \\
\text { (n) }\end{array}$ & $\begin{array}{l}\text { Heterozygotes } \\
\text { (n) }\end{array}$ \\
\hline \multirow{4}{*}{$\begin{array}{l}\text { Collie Eye Anomaly, CEA, } \\
\text { NHEJ1 g.28697542_28705340del7799 }\end{array}$} & Rough Collie & \multirow[t]{4}{*}{2} & \multirow[t]{4}{*}{2} \\
\hline & Lancashire Heeler & & \\
\hline & Shetland Sheepdog & & \\
\hline & $\begin{array}{l}\text { Nova Scotia Duck Tolling } \\
\text { Retriever }\end{array}$ & & \\
\hline \multirow{7}{*}{$\begin{array}{l}\text { Cone-Rod Dystrophy, cord1-PRA/crd4, RPGRIP1 } \\
\text { c.340_341 insA } 29 \text { GGAAGCAACAGGATG }\end{array}$} & Chihuahua & \multirow[t]{7}{*}{5} & \multirow[t]{7}{*}{5} \\
\hline & Chinese Crested Dog & & \\
\hline & Curly Coated Retriever & & \\
\hline & English Springer Spaniel & & \\
\hline & English Toy Terrier & & \\
\hline & Lowchen & & \\
\hline & Swedish Elkhound & & \\
\hline \multirow{2}{*}{$\begin{array}{l}\text { Golden Retriever Progressive Retinal Atrophy 2, Gr-PRA2, } \\
\text { TTC8 c.669delA }\end{array}$} & Golden Retriever & \multirow[t]{2}{*}{1} & \multirow[t]{2}{*}{0} \\
\hline & Labrador Retriever & & \\
\hline \multirow{11}{*}{$\begin{array}{l}\text { PRCD-PRA, } \\
P R C D \text { c.5G }>A\end{array}$} & American Cocker Spaniel & \multirow[t]{11}{*}{28} & \multirow[t]{11}{*}{7} \\
\hline & American Hairless Terrier & & \\
\hline & $\begin{array}{l}\text { Australian Cattle Dog } \\
\text { Bolognese }\end{array}$ & & \\
\hline & Finnish Lapphund & & \\
\hline & Karelian Bear Dog & & \\
\hline & Lancashire Heeler & & \\
\hline & $\begin{array}{l}\text { Nova Scotia Duck Tolling } \\
\text { Retriever }\end{array}$ & & \\
\hline & Portuguese Podengo & & \\
\hline & Portuguese Water Dog & & \\
\hline & Spanish Water Dog & & \\
\hline & Swedish Elkhound & & \\
\hline \multirow{6}{*}{$\begin{array}{l}\text { Primary Lens Luxation, PLL, } \\
\text { ADAMTS17c. } 1473+1 \mathrm{G}>\mathrm{A}\end{array}$} & $\begin{array}{l}\text { Australian Cattle Dog } \\
\text { Chinese Crested Dog }\end{array}$ & \multirow[t]{6}{*}{8} & \multirow[t]{6}{*}{8} \\
\hline & Lancashire Heeler & & \\
\hline & Miniature Bull Terrier & & \\
\hline & Parson Russell Terrier & & \\
\hline & Jack Russell Terrier & & \\
\hline & Tibetan Terrier & & \\
\hline Primary Open Angle Glaucoma, POAG, & Grey Norwegian Elkhound & 5 & 0 \\
\hline ADAMTS10 c. $1159 \mathrm{G}>\mathrm{A}$ & & & \\
\hline
\end{tabular}


Progressive Retinal Atrophy Type III, PRA type III,

FAM161A c.1758-15_1758-16ins238

Progressive Retinal Atrophy, CNGA1-PRA,

CNGA1 c.1752_1755delAACT

Progressive Retinal Atrophy, PAP1_PRA, CNGB1

c.2685delA2687_2688insTAGCTA

Rod-Cone Dysplasia 3, rcd3,

PDE6A c.1940delA
Tibetan Spaniel

Shetland Sheepdog

Papillon

Phalene

Chinese Crested Dog

Pomeranian
2

0

$4 \quad 1$

(1)

(1)

\section{ADAMTS17variant explains less than half of the lens luxation cases}

The gene panel screening cohort included 36 dogs from 17 breeds with either affected or suspected LL (Table 1). The majority of the cases $(66 \%)$ did not carry the ADAMTS17 c. $1473+1 \mathrm{G}>\mathrm{A}$ variant. However, eight dogs were heterozygous and eight homozygous for the variant (Table 3). All of the homozygous cases were affected. Two heterozygotes were LL affected and six LL suspected. Heterozygosity increases the risk of developing the LL phenotype (Farias et al., 2010; Gould et al., 2011).

\section{ADAMTS10variant likely to cause glaucoma in East Siberian Laikas}

The ADAMTS10 c. $2231 \mathrm{G}>\mathrm{A}$ variant was originally described to cause primary open-angle glaucoma in a laboratory colony of beagles (Kuchtey et al., 2011). An ESL owner contacted us, reporting that her dog carries the ADAMTS10 c.2231G $>A$ variant observed in a gene panel screening. To follow up on this finding, we screened the variant in 71 ESLs available in our biobank. We found 10 heterozygotes and one homozygote. The homozygote ESL was reported to have buphthalmos and was euthanized due to blindness at five years of age, both typical signs of complicated glaucoma. One of the heterozygous dogs was reported to have a full sibling with complicated glaucoma. These results suggest that the ADAMTS10 variant causes glaucoma also in ESLs.

\section{Molecular descriptions missing for PRA in many breeds}

PRA is known to be genetically heterogeneous. Our gene panel cohort included 118 PRA cases from 52 breeds (Table 1). We found that 32 out of the 118 dogs (27\%) were homozygous for one of eight retinal phenotype-causing variants (Table 2). The most common variant amongst the PRA cases was the PRCD c.5G>A variant, homozygous in 28 PRA-affected dogs (Table 3 ).

The PDE6A c.1940delA variant causing rcd3 was found in two breeds, Pomeranian and Chinese Crested Dog. The variant explained one of the two affected Pomeranians' phenotype, suggesting the presence of additional PRA variants in the breed. In Chinese Crested Dogs, one LL suspected dog was heterozygous, but the two PRA affected were wild-type, indicating yet another genetic cause of PRA.

In the gene panel cohort, we observed RPGRIP1 insertion homozygotes or heterozygotes in five new breeds: Chihuahuas $(n=3)$, English Toy Terriers $(n=1)$, Lowchens $(n=1)$, Swedish Elkhounds $(n=1)$, and Chinese Crested Dogs $(n=1)(T a b l e ~ 3)$. We further screened 1013 dogs to evaluate carrier frequencies in the new affected breeds and ten additional breeds known to harbor the variant (Table 4). Altogether, 23 RPGRIP1 insertion homozygotes were identified in both screenings. Three homozygous Chihuahuas were identified, of which two were PRA-affected. The owner of the third dog reported that it had been eye examined healthy at three years of age and had no problems with visual acuity by 10 years of age. Three homozygous English Toy Terriers were found, of which two were PRA-affected, and one was not eye examined. Of the 95 Lowchens tested, seven were homozygous for the RPGRIP1 insertion. One of the homozygotes was PRA-affected, and another was reported to have decreased visual acuity at 10 years of age. The other Lowchens had been examined at a young age (1-3 years old) or not at all. Five short-haired Miniature Dachshunds were also found to be RPGRIP1 insertion 
homozygotes, of which one was PRA-affected. Homozygotes were also observed in three other breeds, with no reported signs of PRA: American Staffordshire Terrier $(n=1)$, Beagle $(n=3)$, and long-haired Dachshund $(n=1)($ Table 4). We found heterozygous carriers in nine of the 15 screened breeds (Table 4).

We next screened for the MAP9 deletion, a known early-onset modifier of the RPGRIP1 insertion associated PRA. In the screening, we included the above-mentioned 23 RPGRIP1 insertion homozygous dogs and 757 additional dogs in MAP9 deletion positive breeds found in commercial testing. All RPGRIP1 insertion homozygotes were wild-type for the MAP9 deletion. Only four MAP9 deletion heterozygotes were found, all of which were wild-type for the RPGRIP1 insertion (Table 4).

Table 4. Prevalence of the RPGRIP1 insertion and MAP9 deletion variants in 15 breeds.

\begin{tabular}{|c|c|c|c|c|c|c|c|c|}
\hline \multicolumn{3}{|l|}{ RPGRIP1 } & \multicolumn{2}{|l|}{ MAP9 } & \multirow[b]{2}{*}{$\begin{array}{l}R P G R I P \\
\text { insertion } \\
\text { carrier } \\
\text { frequency }\end{array}$} & \multirow[b]{2}{*}{$\begin{array}{l}\text { Wild- } \\
\text { type } \\
\text { (n) }\end{array}$} & \multirow[b]{2}{*}{$\begin{array}{l}\text { Heterozygotes } \\
\text { (n) }\end{array}$} & \multirow[b]{2}{*}{$\begin{array}{l}\text { MAPg } \\
\text { deletion } \\
\text { carrier } \\
\text { frequency }\end{array}$} \\
\hline Breed & $\begin{array}{l}\text { Samples } \\
\text { (n) }\end{array}$ & $\begin{array}{l}\text { Wild- } \\
\text { type } \\
\text { (n) }\end{array}$ & $\begin{array}{l}\text { Heterozygotes } \\
\text { (n) }\end{array}$ & $\begin{array}{l}\text { Homozygotes } \\
\text { (n) }\end{array}$ & & & & \\
\hline $\begin{array}{l}\text { American } \\
\text { Staffordshire } \\
\text { Terrier }\end{array}$ & 3 & 2 & 0 & 1 & - & 3 & 0 & - \\
\hline Barbet & 21 & 20 & 1 & 0 & $4.8 \%$ & 21 & 0 & - \\
\hline Beagle & 33 & 26 & 4 & 3 & $12.1 \%$ & 33 & 0 & - \\
\hline Chihuahua & 199 & 176 & 20 & 3 & $10.1 \%$ & 199 & 0 & - \\
\hline $\begin{array}{l}\text { Chinese } \\
\text { Crested Dog }\end{array}$ & 105 & 103 & 2 & 0 & $1.9 \%$ & 105 & 0 & - \\
\hline $\begin{array}{l}\text { Coton de } \\
\text { Tulear }\end{array}$ & 25 & 25 & 0 & 0 & - & 23 & 2 & $8.0 \%$ \\
\hline $\begin{array}{l}\text { English Toy } \\
\text { Terrier }\end{array}$ & 115 & 82 & 30 & 3 & $26.1 \%$ & 115 & 0 & - \\
\hline $\begin{array}{l}\text { Long-haired } \\
\text { Dachshund }\end{array}$ & 10 & 9 & 0 & 1 & - & 10 & 0 & - \\
\hline Lowchen & 95 & 51 & 37 & 7 & $38.9 \%$ & 95 & 0 & - \\
\hline $\begin{array}{l}\text { Miniature } \\
\text { long-haired } \\
\text { Dachshund }\end{array}$ & 24 & 24 & 0 & 0 & - & 23 & 1 & $4.2 \%$ \\
\hline $\begin{array}{l}\text { Miniature } \\
\text { short-haired } \\
\text { Dachshund }\end{array}$ & 14 & 4 & 5 & 5 & $35.7 \%$ & 13 & 1 & $7.1 \%$ \\
\hline $\begin{array}{l}\text { Miniature } \\
\text { wire-haired } \\
\text { Dachshund }\end{array}$ & 12 & 11 & 1 & 0 & $8.3 \%$ & 12 & 0 & - \\
\hline $\begin{array}{l}\text { Short-haired } \\
\text { Dachshund }\end{array}$ & 3 & 3 & 0 & 0 & - & 3 & 0 & - \\
\hline $\begin{array}{l}\text { Swedish } \\
\text { Elkhound }\end{array}$ & 94 & 93 & 1 & 0 & $1.1 \%$ & 94 & 0 & - \\
\hline $\begin{array}{l}\text { Wire-haired } \\
\text { Dachshund }\end{array}$ & 27 & 27 & 0 & 0 & - & 27 & 0 & - \\
\hline Total & 780 & 656 & 101 & 23 & $12.9 \%$ & 776 & 4 & $0.5 \%$ \\
\hline
\end{tabular}


To assess the retinal phenotype in a higher resolution, we chose five RPGRIP1 insertion homozygotes (wild-type for the MAP9 deletion, aged 1.3-7.8 years) and three age- and breed-matched controls for spectral-domain optical coherence tomography (SD-OCT) imaging. We did not find observable changes in the retinal thickness between the cases and controls (Online resource 3). Despite the extensive population screening of the MAP9 deletion variant, we did not find homozygotes for imaging. The PRA-affected RPGRIP1 insertion homozygotes were not available for SD-OCT.

As the last example of PRA, we screened the TTC8 c.669delA variant associated with gr2-PRA (Downs et al., 2014) in Finnish Labrador Retrievers (LR) as it has been found in other LR populations. Three heterozygotes were identified in the screening of 190 LRs, indicating a $1.6 \%(3 / 190)$ carrier frequency.

We did not find any causal variant within the 49 tested variants in other retinopathy cases or the dogs affected with PRA and glaucoma (Table 2).

\section{Discussion}

Dogs and humans share significant similarities in eye physiology, and dogs have become a valuable spontaneous animal model to study the genetics and therapeutics of blinding eye diseases. Despite an increasing speed of discovery of new causative variants across canine eye disease groups, the genetic cause in most cases is still expected to remain unknown. We wanted to test this hypothesis by screening 49 known variants in nearly 200 dogs affected with PRA, glaucoma, or lens luxation and validated the results in additional samples from almost 1200 dogs. The panel screening identified causal variants in ten different genes across breeds, including new affected breeds, but explained only $28 \%$ of the studied cases. These results reveal remarkable genetic heterogeneity and highlight the extensive lack of molecular descriptions in canine eye disorders. Our study underlines an urgent need for new molecular discoveries that would be critical not only to improve veterinary molecular diagnostics and the understanding of pathophysiology but also to explore new therapeutic options for the corresponding human eye disorders.

The availability of gene panel screening has made it feasible to quickly and affordably test for the most known variants associated with a given phenotype with important implications. For example, it is assumed that up to half of the diagnosed human eye diseases could be treatable before advancing to deterioration of visual acuity (Assi et al., 2021; Solebo et al., 2017), highlighting the relevance of molecular diagnostic tools for early disease risk prediction. The same could also be true for dogs. We applied a gene panel screening approach with the most up-to-date list of known canine syndromic or nonsyndromic variants, covering over $90 \%$ of OMIA-listed eye disease variants. Yet, over $70 \%$ of the cases remained unexplained. It is possible that some of the phenotypes observed could have been explained by other known variants not included in our gene panel. For example, we missed the variant in the C2ORF71 gene, which causes a late-onset PRA (rcd4) in the Irish Setter breeds (Downs et al., 2013). We had two PRA-affected Irish Setters in the screening but failed to find an associated variant in both. Similarly, seven Miniature Schnauzers affected with PRA and one with overlapping PRA and glaucoma were screened without detected variants. Genetic causes for these cases could be found if the two recent PRA variants had been present in the panel: an intronic variant in the HIVEP3-gene and a structural variant in PPT1-gene (Kaukonen et al., 2020; Murgiano et al., 2018). However, the lack of some of the recent variants in the panel does not change the critical conclusion of the results, highlighting the need for further research in all eye disease groups for progress in the field.

Lens luxation has been associated with a variant in the ADAMTS17gene (Farias et al., 2010; Gould et al., 2011). Most of our cases were not explained by that variant as 20 out of 36 cases were wild-type. These LL cases are likely to harbor another genetic variant, or their phenotype is secondary to an underlying cause due to trauma or other conditions. In humans, the FBN1 gene, which is best known for its association with Marfan- and Weill-Marchesani syndromes with EL and skeletal changes, is also known to cause an isolated EL phenotype, thus making it a possible candidate gene (Comeglio et al., 2002). However, none of the affected dogs in our cohort were reported to have skeletal abnormalities.

Panel screening sometimes reveals unexpected results: in this study, we validated a surprising discovery of the ADAMTS10 glaucoma-associated variant in East Siberian Laikas. The POAG-associated ADAMTS10 variant was originally identified in an 
isolated and inbred laboratory beagle population (Kuchtey et al., 2011). The two breeds are not closely related (Donner et al., 2018; Parker et al., 2017), suggesting that the variant is old or just recreated by chance. The ESL originates from early Russian and Siberian dogs, which come from the areas of the earliest archeological evidence of canids (Shannon et al., 2015). Gene panel screening can result in surprising findings that may not have an immediate explanation. However, the variant appears to cause glaucoma in the ESL breed with a notable carrier frequency (14\%), and gene testing is recommended to eradicate the condition from future populations.

PRA, a retinal disease closely resembling human retinitis pigmentosa, is the most studied eye disorder in dogs with most gene discoveries. We screened over 20 known PRA variants but those explained only $27 \%$ of the cases. Unsurprisingly, many of these cases were homozygous for the PRCD variant, which affects over 40 breeds (Miyadera, Acland, et al., 2012). Many breeds still lack molecular descriptions. The TTC8 variant associated with gr-PRA2 in Labrador Retrievers had a very low frequency (2\%) in the Finnish LRs, correlating with the simultaneous presence of PRA causing PRCD variant and the low number of PRA diagnoses in the breed according to the public database of the Finnish Kennel Club. In addition, we found that the PDE6A variant, which causes rod photoreceptor degeneration through cGMP accumulation (Barbehenn, E et al., 1988; Petersen-Jones et al., 1999), causes PRA in Pomeranians, but is not the only causative variant in the breed as one of the two cases was wild-type for it.

The RPGRIP1 insertion and MAP9 deletion variants have been associated with PRA or its age of onset (Mellersh et al., 2006; Forman et al., 2016; Miyadera et al., 2012). However, the clinical significance of these variants remains unclear with a suggested incomplete penetrance (Das et al., 2017). We screened nearly 800 dogs in 15 breeds and found 23 RPGRIP1 insertion homozygotes and four MAP9 deletion heterozygotes, suggesting a low overall frequency. Despite the low frequencies, we found the RPGRIP1 variant in five new breeds: Chihuahua, Chinese Crested Dog, English Toy Terrier, Lowchen, and Swedish Elkhound. None of the RPGRIP1 insertion homozygotes had the MAP9 variant, and the four MAP9 deletion carriers were wild-type for the RPGRIP1 variant. The MAP9 deletion was heterozygous in two Coton de Tulears, one longhaired Miniature Dachshund and one short-haired Miniature Dachshund. Dachshunds are known to carry the MAP9 deletion (Forman et al., 2016; Miyadera et al., 2012). The MAP9 discovery in Coton de Tulears was new; however, we did not find the RPGRIP1 variant in the breed. None of the PRA-affected dogs carried either variant, suggesting other disease-causing variants in the breed. Of the 23 identified RPGRIP1 insertion homozygotes, six were PRA affected. The average age at diagnosis for the affected dogs was 8.1 years, whereas the other 17 homozygotes had no reported signs of PRA. Ten of the 17 had been ye examined on average at four years old, and the youngest dog was only 1.9 years old at the time of the study. The remaining seven dogs had not been eye examined and were either young or not available for eye examinations. As none of the homozygotes had the early onset modifier, it might be assumed that the symptoms might appear much later in life, or in the case of the oldest homozygotes, have possibly gone unnoticed as eye examinations had not been performed.

The developments in gene therapy highlight the importance of identifying novel risk variants in canine eye diseases. For example, the RPE65 gene, which harbors RP and PRA-associated variants, was the first target for gene therapy development to treat blindness. The therapy was first developed in spontaneous canine models with RPE65 associated PRA and successfully restored the target cells' function (Aguirre et al., 2007; Le Meur et al., 2007; Narfström et al., 2003). Following the success in animal models, the gene-therapy was developed for human use in Leber's congenital amaurosis (Bainbridge et al., 2009; Cideciyan et al., 2008). Since then, gene therapy development has been of constant interest in dog models: at least four genes causing retinal diseases in both species are being studied for gene therapy development. For example, four of these genes were included in the gene panel: RPGR (Beltran et al., 2012), PDE6A (Mowat et al., 2017), BEST1 (Guziewicz et al., 2018), and CNGB3 (Komáromy et al., 2010). Identifying new variants in canine eye disorders can serve as models for human eye disorders and provide additional targets for gene therapy development.

In summary, we have performed the most comprehensive gene panel screening for three common canine eye disorders and report extensive genetic heterogeneity, new affected breeds, and a striking lack of molecular description in most cases. Gene panel tests are already powerful tools for veterinary diagnostics and breeding programs, especially for eye disorders with many variants and many forms of the disease in the breeds, and panels will only get better with improving content over time. 
Simultaneously, the affected breeds and dogs may serve as spontaneous models to human eye disorders to investigate the disease pathophysiology and explore possibilities for new therapeutics powered by the emergence of the latest gene-editing technologies.

\section{Declarations}

\section{Acknowledgements}

We would like to acknowledge the Molecular Medicine Finland core facility (FIMM) at the University of Helsinki for sequencing services and the IT Center for Science Ltd. (CSC, Finland) for providing high-performance computing infrastructure. Sini Karjalainen and Ileana Quintero are thanked for their expert technical help and Oliver Forman for the MAP9 PCR protocol. We are grateful to all dog owners who have donated samples from their dogs for the study.

\section{Funding}

This study was partially supported by the Jane and Aatos Erkko Foundation, Mary and Georg C. Ehrnrooth Foundation, Sigrid Jusélius Foundation, Helsinki Institute of Life Science, and Wisdom Health.

\section{Conflicts of interest}

$\mathrm{HL}$ is a paid consultant, and JD an employee of Genoscoper Laboratories Ltd (Wisdom Health), providing genetic tests for dogs.

\section{Ethics approval}

Sample collection was ethically approved by the Animal Ethics Committee of State Provincial Office of Southern Finland (ESAVI/343/04.10.07/2016 and ESAVI/25696/2020).

\section{Consent to participate}

Written consent was given by the dogs' owners, who donated samples from their dogs.

\section{Consent for publication}

Not applicable

\section{Availability of data and material}

Not applicable

\section{Code availability}

Not applicable

\section{Authors' contributions}

Conceptualization: MK, JD, HL; Design: IP, MK, JD, HL; Investigation: IP, JD; Formal analysis: IP, JD; Writing - original draft: IP, $\mathrm{MK}, \mathrm{HL}$; Writing - editing and review: all; Funding acquisition: $\mathrm{HL}$

\section{References}

Aguirre, G. K., Komáromy, A. M., Cideciyan, A. V., Brainard, D. H., Aleman, T. S., Roman, A. J., Avants, B. B., Gee, J. C., Korczykowski, M., Hauswirth, W. W., Acland, G. M., Aguirre, G. D., \& Aguirre, G. K. (2007). Canine and Human Visual Cortex 
Intact and Responsive Despite Early Retinal Blindness from RPE65 Mutation. PLoS Medicine, 4(6). https://doi.org/10.1371/journal.pmed.0040230

Aguirre-Hernández, J., \& Sargan, D. R. (2005). Evaluation of candidate genes in the absence of positional information: A poor bet on a blind dog! The Journal of Heredity, 96(5), 475-484. https://doi.org/10.1093/jhered/esi092

Assi, L., Chamseddine, F., Ibrahim, P., Sabbagh, H., Rosman, L., Congdon, N., Evans, J., Ramke, J., Kuper, H., Burton, M. J., Ehrlich, J. R., \& Swenor, B. K. (2021). A Global Assessment of Eye Health and Quality of Life. JAMA Ophthalmology. https://doi.org/10.1001/jamaophthalmol.2021.0146

Barbehenn, E, Gagnon, C, Noelker, D, Aquirre, G, \& Chader, G. (1988). Inherited rod-cone dysplasia: Abnormal distribution of cyclic GMP in visual cells of affected Irish setters. Experimental Eye Research, 46(2), 149-159.

https://doi.org/10.1016/S0014-4835(88)80073-3

Bunel, M., Chaudieu, G., Hamel, C., Lagoutte, L., Manes, G., Botherel, N., Brabet, P., Pilorge, P., André, C., \& Quignon, P. (2019). Natural models for retinitis pigmentosa: Progressive retinal atrophy in dog breeds. Human Genetics, 138(5), 441-453. https://doi.org/10.1007/s00439-019-01999-6

Comeglio, P., Evans, A. L., Brice, G., Cooling, R. J., \& Child, A. H. (2002). Identification of FBN1 gene mutations in patients with ectopia lentis and marfanoid habitus. The British Journal of Ophthalmology, 86(12), 1359-1362.

Daiger, S. P., Bowne, S. J., \& Sullivan, L. S. (2007). Perspective on Genes and Mutations Causing Retinitis Pigmentosa. Archives of Ophthalmology, 125(2), 151-158. https://doi.org/10.1001/archopht.125.2.151

Das, R. G., Marinho, F. P., Iwabe, S., Santana, E., McDaid, K. S., Aguirre, G. D., \& Miyadera, K. (2017). Variabilities in retinal function and structure in a canine model of cone-rod dystrophy associated with RPGRIP1 support multigenic etiology. Scientific Reports, 7(1), 12823. https://doi.org/10.1038/s41598-017-13112-w

Dekomien, G., \& Epplen, J. T. (2003). Analysis of PDE6D and PDE6G genes for generalised progressive retinal atrophy (gPRA) mutations in dogs. Genetics, Selection, Evolution: GSE, 35(4), 445-456. https://doi.org/10.1186/1297-9686-35-5-445

Donner, J., Anderson, H., Davison, S., Hughes, A. M., Bouirmane, J., Lindqvist, J., Lytle, K. M., Ganesan, B., Ottka, C., Ruotanen, P., Kaukonen, M., Forman, O. P., Fretwell, N., Cole, C. A., \& Lohi, H. (2018). Frequency and distribution of 152 genetic disease variants in over 100,000 mixed breed and purebred dogs. PLoS Genetics, 14(4).

https://doi.org/10.1371/journal.pgen.1007361

Donner, J., Kaukonen, M., Anderson, H., Möller, F., Kyöstilä, K., Sankari, S., Hytönen, M., Giger, U., \& Lohi, H. (2016). Genetic Panel Screening of Nearly 100 Mutations Reveals New Insights into the Breed Distribution of Risk Variants for Canine Hereditary Disorders. PLOS ONE, 11(8), e0161005. https://doi.org/10.1371/journal.pone.0161005

Downs, L. M., Wallin-Håkansson, B., Bergström, T., \& Mellersh, C. S. (2014). A novel mutation in TTC8 is associated with progressive retinal atrophy in the golden retriever. Canine Genetics and Epidemiology, 1. https://doi.org/10.1186/2052-6687$1-4$

Dreger, D. L., Hooser, B. N., Hughes, A. M., Ganesan, B., Donner, J., Anderson, H., Holtvoigt, L., \& Ekenstedt, K. J. (2019). True Colors: Commercially-acquired morphological genotypes reveal hidden allele variation among dog breeds, informing both trait ancestry and breed potential. PLOS ONE, 14(10), e0223995. https://doi.org/10.1371/journal.pone.0223995

Dvir, L., Srour, G., Abu-Ras, R., Miller, B., Shalev, S. A., \& Ben-Yosef, T. (2010). Autosomal-Recessive Early-Onset Retinitis Pigmentosa Caused by a Mutation in PDE6G, the Gene Encoding the Gamma Subunit of Rod cGMP Phosphodiesterase. American Journal of Human Genetics, 87(2), 258-264. https://doi.org/10.1016/j.ajhg.2010.06.016 
Farias, F. H. G., Johnson, G. S., Taylor, J. F., Giuliano, E., Katz, M. L., Sanders, D. N., Schnabel, R. D., McKay, S. D., Khan, S., Gharahkhani, P., O'Leary, C. A., Pettitt, L., Forman, O. P., Boursnell, M., McLaughlin, B., Ahonen, S., Lohi, H., Hernandez-Merino, E., Gould, D. J., ... Mellersh, C. (2010). An ADAMTS17 Splice Donor Site Mutation in Dogs with Primary Lens Luxation. Investigative Ophthalmology \& Visual Science, 51(9), 4716-4721. https://doi.org/10.1167/iovs.09-5142

Forman, O. P., Pettitt, L., Komáromy, A. M., Bedford, P., \& Mellersh, C. (2015). A Novel Genome-Wide Association Study Approach Using Genotyping by Exome Sequencing Leads to the Identification of a Primary Open Angle Glaucoma Associated Inversion Disrupting ADAMTS17. PLoS ONE, 10(12). https://doi.org/10.1371/journal.pone.0143546

Gould, D., Pettitt, L., McLaughlin, B., Holmes, N., Forman, O., Thomas, A., Ahonen, S., Lohi, H., O’Leary, C., Sargan, D., \& Mellersh, C. (2011). ADAMTS17 mutation associated with primary lens luxation is widespread among breeds. Veterinary Ophthalmology, 14(6), 378-384. https://doi.org/10.1111/j.1463-5224.2011.00892.x

Haim, M. (2002). The epidemiology of retinitis pigmentosa in Denmark. Acta Ophthalmologica Scandinavica, 80, 1-34. https://doi.org/10.1046/j.1395-3907.2002.00001.x

Jeanes, E. C., Oliver, J. A. C., Ricketts, S. L., Gould, D. J., \& Mellersh, C. S. (2019). Glaucoma-causing ADAMTS17 mutations are also reproducibly associated with height in two domestic dog breeds: Selection for short stature may have contributed to increased prevalence of glaucoma. Canine Genetics and Epidemiology, 6, 5. https://doi.org/10.1186/s40575-019-0071-6

Kuchtey, J., Olson, L. M., Rinkoski, T., MacKay, E. O., Iverson, T. M., Gelatt, K. N., Haines, J. L., \& Kuchtey, R. W. (2011). Mapping of the Disease Locus and Identification of ADAMTS10 As a Candidate Gene in a Canine Model of Primary Open Angle Glaucoma: E1001306. PLoS Genetics, 7(2). http://dx.doi.org.libproxy.helsinki.fi/10.1371/journal.pgen.1001306

Lenassi, E., Clayton-Smith, J., Douzgou, S., Ramsden, S. C., Ingram, S., Hall, G., Hardcastle, C. L., Fletcher, T. A., Taylor, R. L., Ellingford, J. M., Newman, W. D., Fenerty, C., Sharma, V., Lloyd, I. C., Biswas, S., Ashworth, J. L., Black, G. C., \& Sergouniotis, P. I. (2020). Clinical utility of genetic testing in 201 preschool children with inherited eye disorders. Genetics in Medicine, 22(4), 745-751. https://doi.org/10.1038/s41436-019-0722-8

Lindblad-Toh, K., Wade, C. M., Mikkelsen, T. S., Karlsson, E. K., Jaffe, D. B., Kamal, M., Clamp, M., Chang, J. L., Kulbokas, E. J., Zody, M. C., Mauceli, E., Xie, X., Breen, M., Wayne, R. K., Ostrander, E. A., Ponting, C. P., Galibert, F., Smith, D. R., deJong, P. J., ... Lander, E. S. (2005). Genome sequence, comparative analysis and haplotype structure of the domestic dog. Nature, 438(7069), 803-819. https://doi.org/10.1038/nature04338

Miyadera, K., Acland, G. M., \& Aguirre, G. D. (2012). Genetic and phenotypic variations of inherited retinal diseases in dogs: The power of within- and across-breed studies. Mammalian Genome: Official Journal of the International Mammalian Genome Society, 23(0), 40-61. https://doi.org/10.1007/s00335-011-9361-3

Morales, J., Al-Sharif, L., Khalil, D. S., Shinwari, J. M. A., Bavi, P., Al-Mahrouqi, R. A., Al-Rajhi, A., Alkuraya, F. S., Meyer, B. F., \& Al Tassan, N. (2009). Homozygous mutations in ADAMTS10 and ADAMTS17 cause lenticular myopia, ectopia lentis, glaucoma, spherophakia, and short stature. American Journal of Human Genetics, 85(5), 558-568.

https://doi.org/10.1016/j.ajhg.2009.09.011

Overwater, E., Floor, K., van Beek, D., de Boer, K., van Dijk, T., Hilhorst-Hofstee, Y., Hoogeboom, A. J. M., van Kaam, K. J., van de Kamp, J. M., Kempers, M., Krapels, I. P. C., Kroes, H. Y., Loeys, B., Salemink, S., Stumpel, C. T. R. M., Verhoeven, V. J. M., Wijnands-van den Berg, E., Cobben, J. M., van Tintelen, J. P., ... Maugeri, A. (2017). NGS panel analysis in 24 ectopia lentis patients; a clinically relevant test with a high diagnostic yield. European Journal of Medical Genetics, 60(9), 465-473. https://doi.org/10.1016/j.ejmg.2017.06.005

Parker, H. G., Dreger, D. L., Rimbault, M., Davis, B. W., Mullen, A. B., Carpintero-Ramirez, G., \& Ostrander, E. A. (2017). Genomic analyses reveal the influence of geographic origin, migration and hybridization on modern dog breed development. Cell 
Reports, 19(4), 697-708. https://doi.org/10.1016/j.celrep.2017.03.079

Petersen-Jones, S. M., Entz, D. D., \& Sargan, D. R. (1999). CGMP Phosphodiesterase-a Mutation Causes Progressive Retinal Atrophy in the Cardigan Welsh Corgi Dog. Investigative Ophthalmology \& Visual Science, 40(8), 1637-1644.

Petersen-Jones, S. M., \& Komáromy, A. M. (2014). Dog Models for Blinding Inherited Retinal Dystrophies. Human Gene Therapy Clinical Development, 26(1), 15-26. https://doi.org/10.1089/humc.2014.155

Shannon, L. M., Boyko, R. H., Castelhano, M., Corey, E., Hayward, J. J., McLean, C., White, M. E., Abi Said, M., Anita, B. A., Bondjengo, N. I., Calero, J., Galov, A., Hedimbi, M., Imam, B., Khalap, R., Lally, D., Masta, A., Oliveira, K. C., Pérez, L., ... Boyko, A. R. (2015). Genetic structure in village dogs reveals a Central Asian domestication origin. Proceedings of the National Academy of Sciences of the United States of America, 112(44), 13639-13644. https://doi.org/10.1073/pnas.1516215112

Solebo, A. L., Teoh, L., \& Rahi, J. (2017). Epidemiology of blindness in children. Archives of Disease in Childhood, 102(9), 853857. https://doi.org/10.1136/archdischild-2016-310532

Suber, M. L., Pittler, S. J., Qin, N., Wright, G. C., Holcombe, V., Lee, R. H., Craft, C. M., Lolley, R. N., Baehr, W., \& Hurwitz, R. L. (1993). Irish setter dogs affected with rod/cone dysplasia contain a nonsense mutation in the rod cGMP phosphodiesterase beta-subunit gene. Proceedings of the National Academy of Sciences of the United States of America, 90(9), 3968-3972.

Wiggs, J. L. (2015). Glaucoma Genes and Mechanisms. Progress in Molecular Biology and Translational Science, 134, 315342. https://doi.org/10.1016/bs.pmbts.2015.04.008

\section{Supplementary Files}

This is a list of supplementary files associated with this preprint. Click to download.

- OnlineResource1.Genotypedgeneticeyediseasevariants.xlsx

- OnlineResource2.Primers.xlsx

- OnlineResource3.OCTimaging.docx 